\title{
Reduced Bone Neoformation in Smoking Rat's Calvaria Grafted with Bone Ceramic
}

\author{
Ronaldo Costa da Fonseca, ${ }^{1 *}$ Tiago José de Macedo Cadidé, ${ }^{1}$ Helton Marzo Dourado Casaes, ${ }^{1}$ Claudemir de \\ Carvalho, ${ }^{2}$ Fabricio Passador-Santos ${ }^{1}$ \\ ${ }^{1}$ Sao Leopoldo Mandic Dental Institute and Research Center, Campinas, SP, Brazil \\ ${ }^{2}$ Dean of Research and Graduate Studies, Centro Universitário Funvic, Pindamonhangaba, SP, Brazil
}

\begin{abstract}
The impact of cigarette smoke on bone grafts in implantodontics has been discussed in the scientific literature. The present study aimed to evaluate bone repair in calvaria of rats after the performance of critical bone defects and graft of bone ceramic biomaterial in animals exposed or not to cigarette smoke. Bone defects of $5 \mathrm{~mm}$ in diameter were made in parietal bone. Each defect was filled with Bone Ceramic biomaterial. Twenty rats were used and divided into 2groups: test, consisting of 10rats exposed to cigarette smoke; and a control group, consisting of 10rats not exposed to cigarette smoke. The animals were euthanized in the $4^{\text {th }}$ postoperative week and bone tissue samples were extracted to perform the histometric analysis. The test group showed less bone neoformation, with statistical significance $(\mathrm{p}<0.05)$ when compared to the control group. We conclude that cigarette smoke had a negative influence on bone neoformation.
\end{abstract}

Keywords: Bone graft, Biomaterials, Bone Ceramic, Cigarette smoke

\section{Introduction}

Bone tissue is a dynamic tissue which is under constant renewal in response to mechanical, nutritional and hormonal influences. Bone tissue metabolism is characterized by two antagonistic and concomitant events: the neoformation of bone tissue by osteoblasts and the resumption of existing bone tissue by osteoclasts, a mechanism known as bone remodeling. ${ }^{1}$ Bone matrix is a biological compound consisting of water, mineral, collagen and non-collagen macromolecules, which are referred to as non-collagenous proteins. ${ }^{2}$ Collagens, have a structural and morph genic role. In mineralized tissues, they interact with several non-collagenous proteins and provide a framework for accommodating mineral crystals. Non-collagenous proteins can be classified briefly into glycoproteins, proteoglycans, proteins derived from plasma, growth factors and other macromolecules. In addition to having a structural function, the bone matrix stores macromolecules that play roles in bio mineralization and cell-matrix interactions, which serve as a reservoir for growth factors and cytokines. When there is any bone injury, such signalling molecules are produced and released activating local bone regeneration. ${ }^{2}$

The ability of the bone tissue to restore original structure and mechanical properties has limitations and may even fail, interrupting or preventing bone repair if vascular supply failure, mechanical instability, excessive defects and/or competing tissues with high capacity proliferative. ${ }^{3}$ However, there are some options that are available to promote and sustain bone neoformation, such as: osteoinduction by growth factors, osteoconduction by grafts and bone substitutes, transfer of stem cells or progenitor cells that differentiate into osteoblasts, osteogenic distraction, and guided bone regeneration. These options may be used isolated or combined. ${ }^{4}$

Bone regeneration is commonly understood as the replacement of lost or deficient bone structure by elements of the same structural organization, so that the lost portion is completely restored in

\begin{tabular}{l|l|}
\hline Quick Response Code: & *Corresponding author: Ronaldo Costa da Fonseca R, Visconde de Barbacena, 86-Centro, \\
44002-584 Feira de Santana-BA, Brazil \\
Received: 08 February, 2021 \\
Citation: Ronaldo CF, Tiago JMC, Helton MDC, Claudemir C, Fabricio PS. Reduced Bone Neofor- \\
mation in Smoking Rat's Calvaria Grafted with Bone Ceramic. SOJ Den Oral Disor. 2021;1(1):1- \\
5. DOI: 10.53902/SOJDOD.2021.01.000504
\end{tabular}


function and structure. Bone tissue has the potential to regenerate its original architecture and some basic conditions need to be present, such as ample blood supply and mechanical stability promoted by a solid base, that is, the pre-existing bone structure. ${ }^{5}$ However, in some defects, surgical procedures are necessary in which bone grafts assist bone repair. ${ }^{6}$

Bone grafts are classified according to its origin (autogenously, allogeneic, xenogenous and alloplastic), the reaction against the host site (bio tolerable, bio inert, bioactive, resorb able), physical characteristics (inorganic, demineralized and fresh) and biological behaviour (osteogenic, osteoinductive, osteoconductive). The autogenously graft is the individual's own tissue. The allogeneic graft is the tissue of another individual of the same species, obtained in a bone bank, where cellular components are eliminated and the osteoinductive and osteoconductive properties are preserved. Xenografts are bone tissues originating from other species. Alloplastic are made from synthetic materials. A bone substitute is an osteoconductor if it conducts bone neoformation promoted by its support structure. Materials that have bone cells capable of promoting bone neoformation are called osteogenic. If they have the biological characteristic of inducing cell differentiation leading to the deposit of new bone, they are called osteoinductors. ${ }^{7}$

Bone graft materials are used in reconstructive surgery to fill the defects, replace bone portions, increase bone size, facilitate or improve the repair of bone defects, provide mechanical support, and stabilize the blood clot. Bone filler must be safe, non-toxic and biocompatible and still be osteogenic, osteoconductive and osteoinductive. 8 The ideal bone substitute attracts the proliferation of new blood vessels and favours bone growth in the grafted region during the repair procedure and is gradually replaced by newly formed bone. ${ }^{9}$

Autogenously grafts have osteogenic, osteoinductive and osteoconductive capabilities and are considered "gold standard". However, when the amount of bone available in the donor areas is insufficient, we have the option of using biomaterials. 6 Biphasic calcium phosphate (BCP-Straumann Bone Ceramic ${ }^{\circledR}$ ), is a biphasic ceramic bone substitute composed of hydroxyapatite (60\%) combined with TCP (40\%). This biomaterial has $90 \%$ porosity, with interconnected pores between 100 and 500microns in diameter, which allows for adequate angiogenesis and cell adhesion. The mechanical stability of the increased volume is maintained thanks to the slow reabsorption of hydroxyapatite that prevents excess reabsorption. ${ }^{10}$

The individual's life habits can interfere with the success of bone repair. Smoking can compromise bone neoneoformation. ${ }^{11,12}$ The components of cigarette smoke, can lead to the death of osteocytes, decreased concentration bone morphogenetic protein (BMP) and alkaline phosphatase, which can also decrease bone mineral density. ${ }^{13,14}$ The negative action of nicotine on Bone density, healing, surgical procedures for grafting and placing dental implants, have been known for a long time. . $^{15,16}$

Several studies have used rat calvaria to assess bone repair through experimental bone defects considering that rat calvaria has a relatively limited blood supplement, which gives it little ability to regenerate spontaneously. ${ }^{17}$ In addition, it is anatomically free from mechanical stress. ${ }^{18}$ Particular importance is given to defects of "critical size", which are large enough so that their spontaneous repair does not occur. This concept aims to assess the real osteogenic potential of a graft. As a method of quantification and comparison of tissues present in histological sections, histometry is widely used. ${ }^{19-23}$

In view of the high number of individuals who smoke and need regenerative surgical procedures, the objective of this study was to evaluate the effects of cigarette smoke on the process of bone graft repair.

\section{Materials and Methods}

Ten male Wistar rats (Rattus norvegicus), weighing between 300 and $400 \mathrm{~g}$, kept in two groups of five, under controlled conditions of temperature and light/dark cycle, with free access to commercial rat food and water, were subjected to three daily exposures to the smoke of ten cigarettes.

Each exposure lasted eight minutes and was repeated three times a day, for 60 consecutive days. ${ }^{24}$ Commercial brand cigarettes available on the market were used, containing $1.10 \mathrm{mg}$ of nicotine, $16.5 \mathrm{mg}$ of tar and $15.2 \mathrm{mg}$ of carbon monoxide each cigarette, as reported by the manufacturer on the packaging. For exposure to cigarette smoke, a transparent acrylic box with a lid was used. ${ }^{24}$

After 60days of exposure to cigarette smoke, the animals had the experimental cavity filled with Bone Ceramic graft. The Ethics Committee on the Use of Animals-CEUA SLMandic 2010/0349, previously approved all procedures. Prior to surgery, the animals were anesthetized with $0.5 \mathrm{~mL} / 100 \mathrm{~g}$ of body weight intramuscularly, using a combination of Ketamine Chlorinate (Franco tar ${ }^{\circledR}$-Virbac) (5\%) and Xylazine Hydrochloride (Virbaxil ${ }^{\circledR}$ Virbac) (2\%). The tracheotomy of the median region of the animal's skullcap was performed, extending from the front-nasal portion to the occipital region, with the aid of a razor. Skin antisepsis was performed with $10 \%$ polyvinyl pyrrolidone (Providing Degermante ${ }^{\circledR}$-Johnson Wax) (PVP-I). Aiming to reduce the trans operative bleeding and promote greater comfort in the immediate postoperative period, sterile fenestrated surgical fields were positioned and $0.2 \mathrm{ml}$ of local anaesthetic was administered based on Lidocaine Hydrochloride with Adrenaline (Lidocaine with Epinephrine 1:100,000-DFL ), at a concentration of 1:100,000.

The surgery consisted of a linear incision in the sagittal midline, through the skin and periosteum, extending from the front nasal region to the outer occipital protuberance, with number 15 scalpel blades. After complete soft tissue dieresis, osteotomies of the skullcap were performed with the aid of $5 \mathrm{~mm}$ diameter trephine drills (Nobel Bio care implant system), mounted at an angle, driven by an electric motor (Figure 1), under constant irrigation with $0.9 \%$ saline chloride solution. Osteotomies created circular defects of $5 \mathrm{~mm}$ in diameter, located in the parietal regions, taking care not to injure the dura. The cavities produced were filled with Bone Ceramic $^{\circledR}$ (Figure 2). 


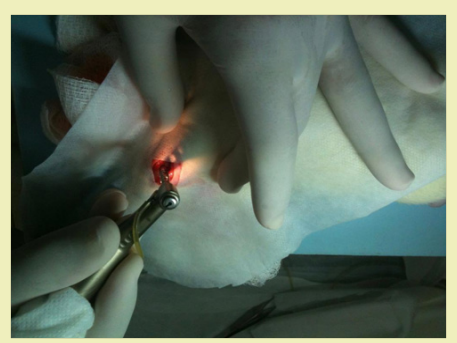

Figure 1: Construction of the bone defect with a drill bit.

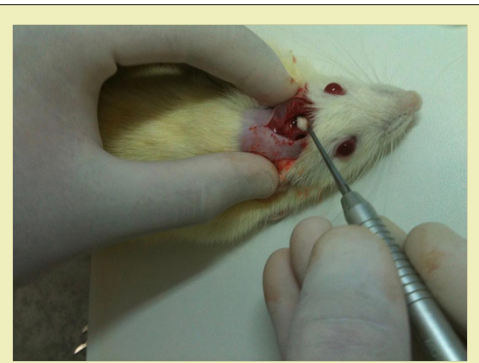

Figure 2: Filling the bone defect with Bone Ceramic ${ }^{\circledR}$.

The suture of the wounds was performed in an interrupted way, with simple stitches, for periosteum and in a continuous scalloped way for the skin. The suture thread was made of polyamide (5-0mononylon) (Ethicon-Johnson\&Johnson). After the surgical procedure, the surgical wound was cleaned with saline solution and the animals were kept in individual cages, for a period of approximately 60 minutes, until recovery from anaesthesia, when they were then taken to the collective cage.

The animals in each group were euthanized four weeks after the experiment with a lethal dose via intramuscular of anaesthetic. After euthanasia, the skullcap was obtained through a full-thick- ness trapezoidal incision, covering the soft tissues of the parietal region. The resection of the entire shell was performed with the aid of a carbide surgical drill type 701 (Implants-Dentoflex Biomaterials Surgical Instruments), mounted in a straight piece and driven by an electric micro motor. The same procedures were performed with ten other animals that were not subjected to cigarette smoke.

The pieces were fixed in $10 \%$ buffered formalin, at room temperature, and then decalcified in $20 \%$ sodium citrate solution and $50 \%$ formic acid in equal parts (Morse's solution), following the routine laboratory procedure for paraffin inclusion. The slides obtained were stained with hematoxylin and eosin (H.E.). With the aid of an image analysis program (Motic ${ }^{\circledR}$ Image 3.2 Motic Inc., Toronto. Canada) three histological parameters were evaluated: left stump, right stump, and central area. The Motic ${ }^{\circledR}$ Image program allows the contour of the areas with bone allowing the calculation of the percentage of bone present in the area of $1 \mathrm{~mm}^{2}$. To measure the newly formed bone tissue, linear measurement (perimeter) was used. Initially, sections stained in H.E. were examined using optical microscopy at 40x magnification to ensure complete visualization of the original bone defect. For the measurements of the newly formed bone area, the program was calibrated for viewing at $100 \mathrm{x}$ magnification, which allowed the identification and histological differentiation of the structures. The total area of newly formed bone inside the defect was given by the sum of the measurements made on each slide and later added to the measurements referring to the other slides of the same defect and the simple average was calculated. The value was expressed in square micrometres.

All procedures were performed with 10 other animals not exposed to cigarette smoke (controls) that had the experimental cavity filled with Bone Ceramic ${ }^{\circledR}$ bone graft.

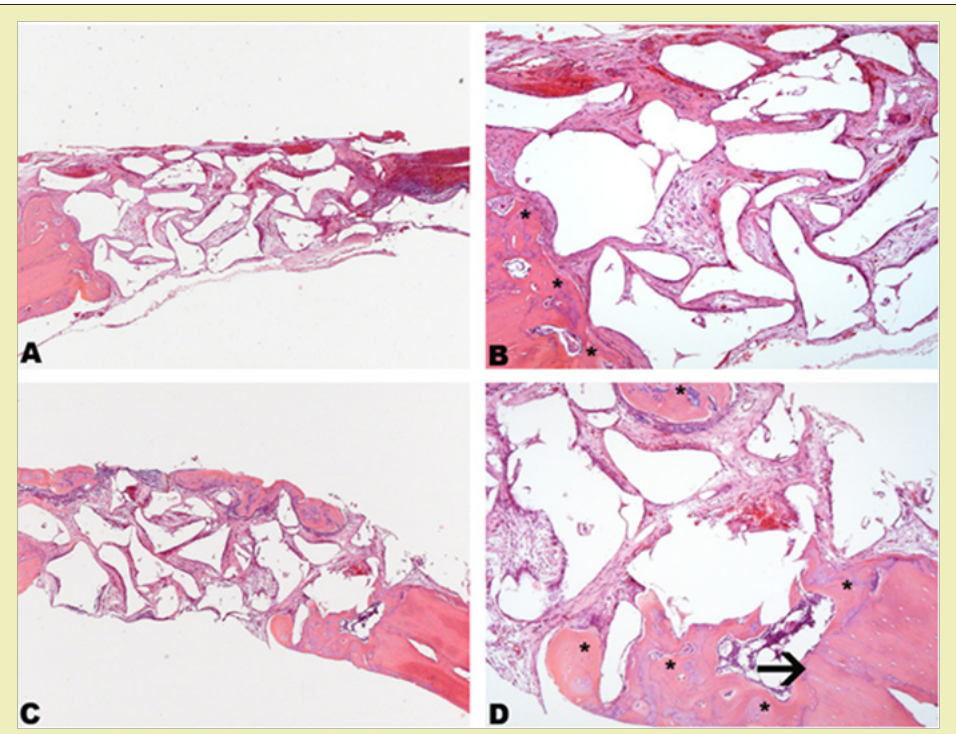

Figure 3: Histological images of critical bone defects after grafting with Bone Ceramic $₫$, in rats exposed or not to cigarette smoke. A-Bone defect in an animal exposed to cigarette smoke: a small amount of newly formed bone tissue is observed in a region adjacent to the remaining bone tissue stump on the left, light-looking biomaterial particles and dense connective tissue (HE, 40x magnification). B- Larger image (100x) highlighting newly formed bone tissue (asterisks) adjacent to the remaining bone stump. Particles of biomaterial (uneven clear spaces) and dense connective tissue (H.E. 100x magnification) are also evident. C- Bone defect in animals not exposed to cigarette smoke: new bone tissue is observed in a region adjacent to the remaining bone tissue stump on the right, biomaterial particles with a clear aspect and dense connective tissue. There is also neoformed bone tissue at the top of the specimen (H\&E, 40x magnification). D- Image showing neoformed bone tissue (asterisks) next to the remaining bone stump and in the upper portion of the specimen. The arrow indicates a basophilic line between the remaining bone tissue stump and the newly formed bone tissue (H\&E, 100x magnification). H\&E-hematoxylin and eosin. 


\section{Results}

Histological analysis of slides stained with HE of bone defects filled by Bone Ceramic $^{\circledR}$, in animals exposed or not to cigarette smoke, revealed a smaller increase in bone neoformation in animals that were exposed to cigarette smoke, despite the effect caused by cigarette smoke. Cigarette has not prevented bone neoformation. A reduction in this parameter was noticeable when the two groups of animals (test and control) were compared. However, the pattern of bone neoformation was similar, observing the neoformation of new bone predominantly from the remaining bone tissue stumps and, to a lesser extent, in some areas between the particles of the biomaterial. In these areas, small bone trabecular were noted (Figure 3). The descriptive and exploratory analysis of the data indicated heterogeneous variances between the groups. Thus, the comparison between the groups that received or did not smoke cigarettes was performed by the $t$ test for heterogeneous variances. All analyses were performed using the R program. R: A language and environment for statistical computing. R Foundation for Statistical Computing, Vienna, Austria. URL https://www.R-project.org/), considering the significance level of $5 \%$.

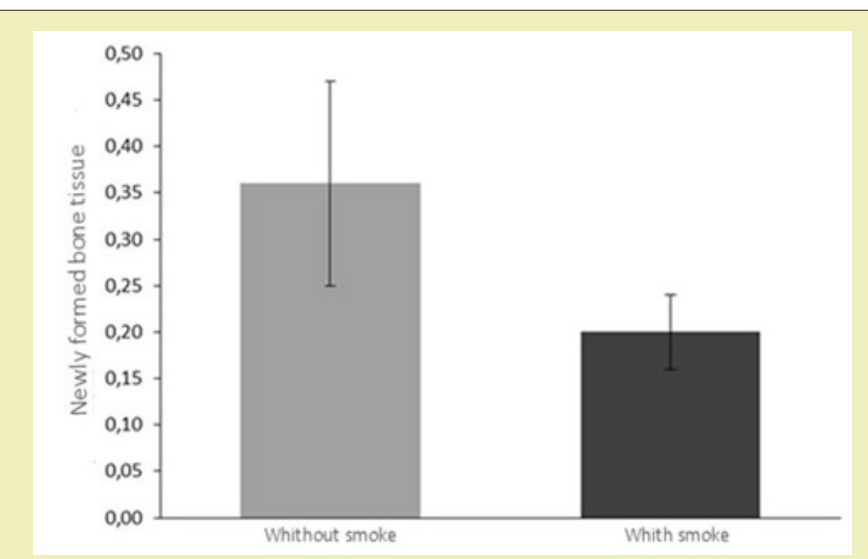

Figure 4: Average and standard deviation of the amount of newly formed bone tissue as a function of exposure or not to cigarette smoke.

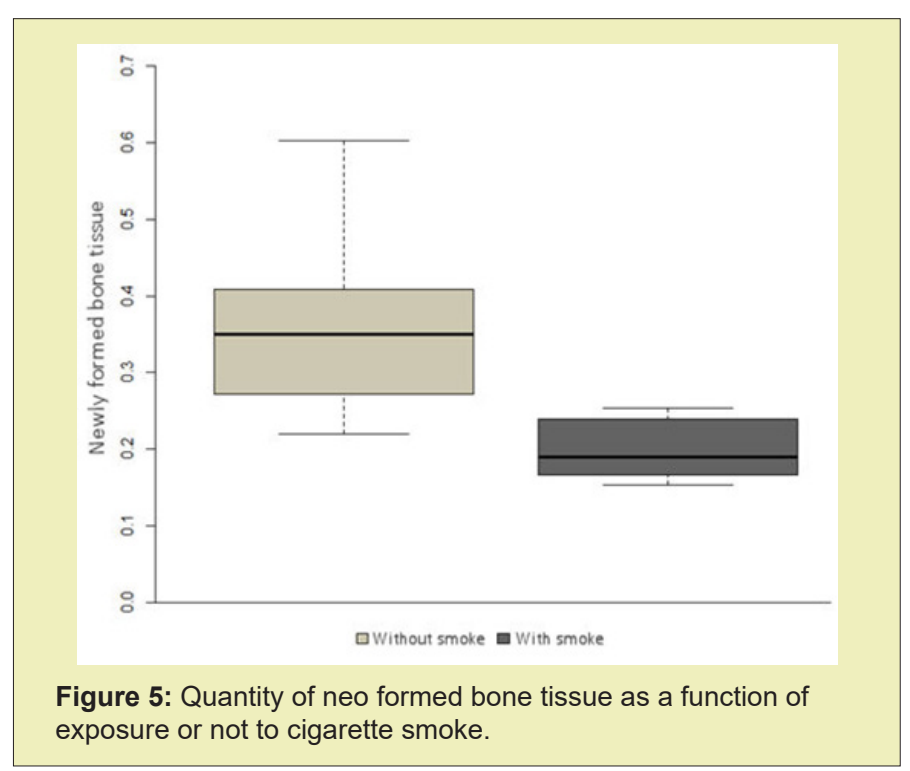

Figures $4 \& 5$ show that the group that received cigarette smoke had less informed bone tissue than the other group $(\mathrm{p}<0.05)$. In the present study, two five-millimetre defects were performed in the parietal bone of rats. ${ }^{25}$ Such holes are said to be critical precisely because they do not heal completely during the period of the experiment, ${ }^{26}$ pointing out incomplete healing in orifices of five millimetres after eight weeks.

Alloplastic materials can be used as a primary or secondary option in bone reconstructions; however, they have some disadvantages such as rejection, infection, extrusion and toxicity. ${ }^{27,28}$ Faster and better results are obtained when the sites are previously decorticalized and perforated. ${ }^{29}$ In this experiment, it was not possible to perform decorticalization due to the thin thickness of the bone tissue of the regions chosen for the defects, only the periosteum was removed. However, in our view, this procedure did not interfere with the results.

Currently the effects that cigarette smoke promotes on the individual have been the object of study by several researchers. The present study histometrically evaluated the influence of cigarette smoke on the bone neoformation process in bone defects grafted with Bone Ceramic ${ }^{\circledR}$ in rats and confirmed results described in some previous studies, demonstrating that cigarette smoke can cause negative effects to the bone repair process..$^{24,30,31}$ Experiments using cigarette smoke inhalation are the closest to the condition of smokers.

Other studies have also presented the deleterious effects of cigarette smoke and its derivatives on bone repair tissues ${ }^{24,32}$ as a decrease in vascularization, ${ }^{33}$ inhibition of osteoplastic differentiation ${ }^{34}$ and stimulating osteoplastic differentiation and the reabsorption of calcium phosphate (an element that is present in greater quantity in bone), ${ }^{35}$ effects that can be observed through histometry. Nicotine can interfere in the healing areas of bone grafts because it promotes vasoconstrictor effect in micro vessels thus inhibiting angiogenesis, an essential event for the nutrition of cells in the initial graft revascularization. ${ }^{33}$

\section{Conclusion}

Bio ceramics are non-toxic bioactive that is durable material that can undergo interfacial interactions with surrounding tissue. The interaction between bone ceramic and surrounding tissue was satisfactorily demonstrated by the histometric method in non-smoking rats, in which a large amount of vital bone can be observed. However, the cigarette smoke had a negative influence on bone neoformation, reducing the amount of newly formed bone in smoking rats when compared to the control group.

\section{Acknowledgments}

None.

\section{Funding}

None.

\section{Conflicts of interest}

Author declares that there is no conflict of interest. 


\section{References}

1. Garant PR. Bone. In: Garant PR, editor, Oral Cells and Tissues. Carol Streams: Quintessence Books, 2003: p. 195-238.

2. Godring SR. Inflammatory mediators as essential elements in boneremodelling. Calcif Tissue Int. 2003;73(2):97-100.

3. Christoffersen J, Landis WJ. A contribution with review to the description of mineralization of bone and other calcified tissues in vivo. Anat Rec. 1991;230(4):435-450.

4. Mark-Júnior SC, Popoff SN. Bone cell biology: the regulation of development, structure and function in the skeleton. Am J Anat. 1988;183(1):1-44.

5. Bosshard DD, Shenk RK. Biologic basis of bone regeneration. In: Buser D. 20 years of guided bon regeneration. $2^{\text {nd }}$ ed. Chicago: Quintessence Publishing Co, Inc, 2009. p.15-45.

6. Caria PH, Kawachi EY, Bertran CA, et al. Biological assessment of porousimplant hydroxyapatite combined with periosteal grafting in maxillary defects. J Oral Maxillofac Surg. 2007;65(5):847-854.

7. Gutierres M, Lopes MA, Hussain NS, et al. Bone Substitutes: general concepts and current status. Arq Med. 2006;19(4):153-162.

8. Finkemeier CG. Bone-grafting and bone graft substitutes. J Bone Joint Surg. 2002;84(3):454-464.

9. Jensen SS, Broggini N, Hjorting-Hansen E, et al. Bone healing and graft resorption of autograft, anorganic bovine bone and b-tricalcium phosphate. A histologic and histomorphometric study in the mandibles of minipigs. Clin oral implants res. 2006;17(3):237-243.

10. Daculsi G, Weiss P, Bouler J-M, et al. Biphasic calcium phosphate/ hydrosol be polymer composites: a new concept for bone and dental substitution biomaterials. Bone. 1999;25(2 Suppl):59S-61S.

11. Soares EA, Fávaro WJ, Cagnon VHA, et al. Effects of alcohol and nicotine on the mechanical resistance of bone and bone neoformation around hydroxyapatite implants. J Bone Miner Metab. 2010;28(1):101-107.

12. Andrade AR, Sant'Ana DCM, Mendes Junior JA, et al. Effects of cigarette smoke inhalation and coffee consumption on bone formation and osseous integration of hydroxyapatite implant. Braz J Biol. 2013;73(1):173-177.

13. Zheng LW, Ma L, Cheung LK. Changes in blood perfusion and bone healing induced by nicotine during distraction osteogenesis. Bone. 2008;43(2):355-361.

14. Berley J, Yamano S, Sukotjo C. The effect of systemic nicotine on osseointegration of titanium implants in the rat femur. J Oral Implantol. 2010;36(3):185-193.

15. Jones JK, Triplett RG. The relationship of cigarette smoking to impaired intraoral wound healing: A review of evidence and implications for patient care. J Oral Maxillofac Surg. 1992;50(3):237-239.

16. Broulik PD, Jarab J. The Effect of Chronic Nicotine Administration on Bone Mineral Content in Mice. Horm Metab Res. 1993;25(4):219-221.

17. Schmitz JP, Holliger JO. The critical size defect as an experimental model for craniomandibulofacial non-unions. Clin Orthop Relat Res. 1986;205:299-308.

18. Mankani MH, Kuznetsov SA, Wolfe RM, et al. In Vivo Bone Formation by Human Bone Marrow Stromal Cells: Reconstruction of the Mouse Calvarium and Mandible. Stem Cells. 2006;24(9):2140-2149.
19. Fredericks DC, Nepola JV, Baker JT, et al. Morphometric effects of pulsed electromagnetic fields on bone healing in a rabbit tibial osteotomy model. J Orthop Trauma. 2000;14(2):93-100.

20. Pryor ME, Yang J, Plimeni G, et al. Analysis of rat calvaria defects implanted with a platelet-rich plasma preparation: radiographic observations. J Periodontol. 2005;76(8);1287-1292.

21. Furlaneto FAC, Nagata MJH, Fucini SE, et al. Bone healing in critical-size defects treated with bioactive glass/calcium sulfate: a histologic and histometric study in rat calvaria. Clin Oral Implants Res. 2007;18(3):311318.

22. Oliveira RC, Oliveira FHG, Cestari TM, et al. Morphometric evaluation of the repair of critical-size defects using demineralized bovine bone and autogenous bone grafts in rat calvaria. Clin Oral Implants Res. 2008;19(8):749-754.

23. Macedo RM, Lacerda SA, Okamoto R, et al. Autogenous Bone and Biphasic Calcium Phosphate Bioceramic in Extraction Sockets of Rats: Histological, Histometric, and Immunohistochemical Evaluation. Implant Dentistry. 2018;27(6):615-622.

24. Nociti Junior FH, Cesar Neto JB, Carvalho MD, et al. Bone density around itanium implants may be influenced by intermittent cigarette smoke inhalation: A histometric study in rats. Int J Oral Maxillofac Implants. 2002;17(3):347-352.

25. Bosch C, Melsen B, Vargevik K. Importance of the critical-size bone defect in testing bone-regenerating materials. J Craniofac Surg. 1998;9(4):310316.

26. Petridis X, Diamanti E, Trigas GC, et al. Bone regeneration in criticalsize calvarial defects using human dental pulp cells in an extracellular matrix-based scaffold. J Cranio-Maxillofac Surg. 2015;43(4):483-490.

27. Dahlin C, Alberius P, Linde A. Osteopromotion for cranioplasty. An experimental study in rat using a membrane technique. J Neurosurg. 1991;74(3):487-491.

28. Keskin M, Mustafa K, Christopher PK, et al. Repairing critical sized rat calvarial defects with a periosteal cell-seeded small intestinal submucosal layer. Plast Reconstr Surg. 2008;122(2): 400-409.

29. Carvalho PSP, Vasconcelos LW, Pi J. Influence of bed preparation on the incorporation of autogenous bone grafts: a study in dogs. Int J Oral Maxillofac Implants. 2000;15(4):565-570.

30. Hollinger JO, Schmitt JM, Hwang K, et al. Impact of nicotine on bone healing. J Biomed Mat Res. 1999;45(4):294-301.

31. Saldanha JB, Pimentel SP, Casati MZ, et al. Histologic evaluation of the effect of nicotine administration on bone regeneration. A study in dogs. Braz Oral Res. 2004;18(4):345-349.

32. Kanis JA, Johnell O, Oden A, et al. Smoking and fracture risk: a metaanalysis. Osteoporos Int. 2005;16(2):155-162.

33. D'Avila S, Reis LD, Piattelli A, et al. Impact of Smoking on Human Bone Apposition at Different Dental Implant Surfaces: A Histologic Study in Type IV Bone. J Oral Implantol. 2010;36(2):85-90.

34. Theiss SM, Boden SD, Hair G, et al. The Effect of Nicotine on Gene Expression During Spine Fusion. Spine. 2000;25(20):2588-2594.

35. Galia CR. Physico-chemical characterization of lyophilized bones of bovine and human origin. Rev Col Bras Cir. 2009;36(2):157-160. 